\title{
Oxidative Stress Biomarkers Response to Exercise in Brazilian Junior Soccer Players
}

\author{
Camila S. C. da $\operatorname{Costa}^{1}$, Márcio A. Barbosa ${ }^{2}$, Juliano Spineti ${ }^{3}$, Cristiana M. Pedrosa ${ }^{1}$, Anna Paola T. R. \\ Pierucci $^{1^{*}}$
} ${ }^{1}$ Universidade Federal do Rio de Janeiro (UFRJ), Instituto de Nutrição Josué de Castro, Departamento de Nutrição Básica e Experi-
mental, Cidade Universitária, Rio de Janeiro, Brazil; ${ }^{2}$ Fluminense Football Club, Centro de Treinamento Vale das Laranjeiras, Duque
de Caxias, Brazil; ${ }^{3}$ UFRJ, Escola de Educação Física e Desportos, Rio de Janeiro, Brazil.
Email: ${ }^{*}$ pierucci@nutricao.ufrj.br

Received February $9^{\text {th }}, 2011$; revised April 19 ${ }^{\text {th }}, 20111$; accepted April 26 $6^{\text {th }}, 2011$.

\begin{abstract}
The purpose was to analyze biomarkers of oxidative stress and muscle damage in junior soccer players undergoing intermittent exercise to verify the biochemical changes. Ten trained, healthy male soccer players (age $18.3 \pm 0.7$ years, body mass $74.3 \pm 7.4 \mathrm{~kg}$, height $175.5 \pm 6.7 \mathrm{~cm}$, body mass index $24.14 \pm 1.15 \mathrm{~kg} / \mathrm{m}^{2} ;$ mean $\pm S D$ ) from the junior category of an elite Brazilian football association participated in this study. They accomplished a running test (Loughborough Intermittent Shuttle Test) which simulates common soccer activity patterns. Blood samples were collected before, during and immediately after the exercise for glucose, lactate, creatinine, urea, ascorbic acid, total plasma antioxidant potential, lipid hydroperoxides, malondialdehyde and creatine kinase concentrations. During the exercise no changes were observed in biomarkers, but, immediately after there was a significant decrease in total plasma antioxidant potential (ranging from $650.37 \pm 66.53 \mu \mathrm{mol} \cdot \mathrm{L}^{-1}$ to $559.95 \pm 91.38 \mu \mathrm{mol} \cdot \mathrm{L}^{-1}, p<0.05$ ) while malondialdehyde and creatine kinase had increased (ranging, respectively, from $6.69 \pm 0.81 \mu \mathrm{mol} \cdot \mathrm{L}^{-1}$ to $8.35 \pm 0.83 \mu \mathrm{mol} \cdot \mathrm{L}^{-1}$ and from $272.01 \pm$ 49.67 U.I. $\cdot L^{-1}$ to $304.65 \pm 39.13$ U.I. $L^{-1}, p<0.05$ ). Findings suggest that the exercise protocol induced significant changes in oxidative stress selected biomarkers in the early stage of recovery. Thus, taking into account that soccer players' competitive careers initiate very precociously being under constant physical exhaustion, further research on junior soccer players' physiology and health are important for more effective physical and nutritional programming.
\end{abstract}

Keywords: Lipid Peroxidation, Creatine Kinase, Athletes, Health

\section{Introduction}

Professional soccer is considered an endurance sport [1] characterized as an intermittent activity with bursts of intense effort [2]. The activity pattern of players during a match involves standing, walking, jogging, cruising, sprinting and backing [3]. Because of the game duration, soccer is mainly dependent upon aerobic metabolism and the average work intensity is close to the anaerobic threshold $[3,4]$. On the other hand, actions such as sprints, heels and kicks may be decisive in a soccer match, so it is accepted that anaerobic efforts are also an important key to success in the sport [4,5].

Exercise might not always be healthy in competitive levels, due to dehydration, substrate depletion, muscle damage, inflammation and increased free radicals (FR) production $[6,7]$. FR are reactive compounds naturally produced in human body, which can exert positive (e.g. on the immune system and antioxidant defenses) or negative effects (e.g. lipid, protein and DNA oxidation) effects over athletic performance, depending on the workload and individual physical conditioning [6-8]. To limit the harmful effects of FR during intense exercise the organism requires enzymatic (catalase, glutathione peroxidase, superoxide dismutase) and non enzymatic (e.g. vitamins $\mathrm{A}, \mathrm{C}$ and E) antioxidant defense systems [9]. Nevertheless, if FR production is greater than the antioxidant system ability to render them inactive, oxi- dative stress (OS) can occurs. Consequently, cellular losses of redox homeostasis permits cell damages and muscle injuries $[7,8]$.

During competitive seasons soccer players have an intense routine of games and training. The physiological and biochemical parameters related to OS are normally altered throughout the 72 hours recovery period $[10,11]$. 
Thus, early recovery from exercise must be essential to maintain and promote good performance and health in those athletes. Investigations related to OS and exercise were carried by the assessment of biomarkers approaching antioxidant defense system, lipid oxidation and muscle damage $[8,12,13]$. Such parameters can be altered during and after exercise, depending on individual metabolic adaptation, nutrition status and also by the use of dietetic antioxidants $[12,14]$.The knowledge about the initial stage of changes in OS biomarkers has not been properly verified but would help in the adoption of optimum procedures in this context.

Soccer players' competitive careers initiate very precociously being exposed to prolonged constant physical exhaustion. In Brazil, for example, the junior category participates in two or three championships simultaneously, such as the Brazilian Junior Championship, which occur almost all year long, Libertadores and South American Cup. Therefore, studying junior soccer players' health ecology is important in more effective programming of their physical and nutritional preparation.

Some studies have used the Loughborough Intermittent Shuttle Test (LIST) [15] as an exercise protocol [1618] to simulate matches due to the lack of control in many variables, such as type and intensity of the activity performed during a game. However, only a few studies evaluated OS parameters during and immediately after the LIST practice and were carried among adults and non professional soccer players $[11,19]$. Such approach in the junior category of soccer players is novel and would provide support for the development of strategies for a satisfactory recovery from intense physical events during championship seasons. Thus, the objective was to evaluate selected biomarkers of OS and muscle damage in junior soccer players, during and immediately after the LIST.

\section{Methods}

Ten trained, healthy male soccer players from the junior category of an elite Brazilian football association took part in this study. The players were informed about the experimental procedures and possible discomforts associated with the study, and a written informed consent was obtained. The study was approved by the Ethics Committee of the Instituto de Estudos em Saúde Coletiva of the Universidade Federal do Rio de Janeiro, Brazil. The subjects characteristics were in average: age $18.3 \pm 0.7$ years, body mass $74.3 \pm 7.4 \mathrm{~kg}$, height $175.5 \pm 6.7 \mathrm{~cm}$, body mass index $24.14 \pm 1.15 \mathrm{~kg} \cdot \mathrm{m}^{-2}$, body fat percentage $12.6 \% \pm 1.7 \%$ (according to Jackson \& Pollock) [20] and maximal oxygen uptake $\left(\mathrm{VO}_{2 \max }\right) 57.8 \pm 1.9 \mathrm{ml} \cdot \mathrm{kg}^{-1} \cdot \mathrm{min}^{-1}$ (according to Léger \& Lambert) [21].

Soccer players were instructed not to change their normal eating habits during the entire period of data collection. They reported to the football club training center on the day of experiment after an overnight fast of 8 hours. Then, consumed a standard breakfast adjusted for individual energy requirements [22]. Before the LIST, the participants answered a $24 \mathrm{hr}$ recall to assess energy and macronutrients dietetic intake, which were analyzed using the software NutWin (2003, Universidade de São Paulo, Brazil). In the sequence, a cannula was inserted into an antecubital vein before the start of the exercise protocol, which was conducted in the grass field at ambient temperature $\left(30^{\circ} \mathrm{C}\right)$, maintaining the ecological variables of a soccer match. The LIST was performed according to Nicholas et al [16] and comprised 20 m shuttles of varied intensity (walking, sprint, jogging-55\% $\mathrm{VO}_{2 \max }$, cruising-95\% $\left.\mathrm{VO}_{2 \max }\right)$ continuously during 15 min, separated by $3 \mathrm{~min}$ of passive recovery, totalizing $90 \mathrm{~min}$ and 5 batteries of exercise. Heart rate (HR) was monitored in $15 \mathrm{~s}$ intervals during the LIST and a competitive soccer game (Tournament Octávio Pinto Guimarães-OPG) with all the participants. The determination of sweat loss during the LIST was performed by monitoring the weight and water intake (ad libitum) of subjects along the experiment.

Blood samples were collected before (Pre), during (D) and post exercise (PE) into heparinized tubes. A whole blood aliquot was separated into capillary tubes for haematocrit analysis [12] aiming the correction of plasma analyses at $\mathrm{D}$ and $\mathrm{PE}$. The remaining freshly withdrawn blood was immediately centrifuged at $3000 \mathrm{rpm}$ for 10 min and aliquots of plasma was separated into cryotubes, frozen at $-80^{\circ} \mathrm{C}$ for later analysis of ascorbic acid (AA), lipid hydroperoxides (LOOHs), malondialdehyde (MDA), total plasma antioxidant potential (TAP), and at $-20^{\circ} \mathrm{C}$ for glucose, lactate, creatinine, urea and creatine kinase (CK).

Glucose, lactate, creatinine, urea and CK plasma concentrations were spectrophotometrically assessed using respecttively commercial test kits [DOLES-10231810084 (Goiás, Brazil)/K084-2 BIOCLIN-10269360143 (Minas Gerais, Brazil)/DOLES-10231810014/DOLES-10231810007/ DOLES-10231810072]. Plasma AA was quantified by high-performance liquid chromatographic [23] (HPLCShimadzu LC-2010) using AA external standard curve (10-50 $\mu \mathrm{mol} /$ Supelco). Plasma LOOHs were determined by the xylenol orange version 2 (FOX2) methods [24], coupled with the selective hydroperoxide reductant triphenylphosphine (TPP) [25], using hydrogen peroxide $\left(\mathrm{H}_{2} \mathrm{O}_{2}\right)$ standard curve $(5-50 \mu \mathrm{mol} /$ Merck $)$. Plasma MDA was determined by HPLC (Shimadzu LC-2010) [26], using 1,1,3,3-tetraethoxypropane standard curve (0 - $50 \mathrm{nmol} /$ Sigma) for quantification. TAP was determined by the assay of ferric plasma reducing ability 
(FRAP) [27] and values were expressed as AA equivalents by linear regression from AA standard curve (90 $720 \mu \mathrm{mol})$.

Analysis of variance (ANOVA) with repeated measures was used to establish significant differences from baseline results. Significant main effects and interactions were further analyzed using Tukey's post hoc test. A paired sample $t$ test was used to determine differences between LIST and soccer HR data. P-values below 0.05 were considered statistically significant and data are presented as means and standard deviations (mean $\pm \mathrm{SD}$ ). There was no loss of data or subjects during research and the results from blood analysis are presented as the mean of all subjects.

\section{Results}

Energy and macronutrient intake of subjects (energy $3253 \pm 318 \mathrm{kcal} /$ day, carbohydrate $6.1 \pm 0.7 \mathrm{~g} / \mathrm{kg}$ weight/ day, protein $1.7 \pm 0.2 \mathrm{~g} / \mathrm{kg}$ weight/ day, fat $1.4 \pm 0.3 \mathrm{~g} / \mathrm{kg}$ weight/ day) were in accordance with the recommendations for physically active adult men [22]. The peak HR during the game was $197 \pm 4 \mathrm{bpm}$ while during LIST was $191 \pm 3 \mathrm{bpm}$. The mean HR during the match $(175 \pm$ $5 \mathrm{bpm})$ was significantly higher $(p<0.05)$ than the LIST $(162 \pm 3 \mathrm{bpm})$. The total weigh loss of subjects $(1.45 \pm$ $0.27 \mathrm{~kg}$ - weight loss + fluid intake), corresponded to $1.94 \% \pm 0.33 \%$ of the mean body mass, which may not compromise physical performance accordingly to the recommendations [22].

The plasma glucose concentrations had a slight numerical decrease in PE vs. Pre (Table 1). There were significant differences $(p<0.05)$ in plasmatic lactate among blood samples, being elevated at D and PE vs. Pre values (Table 1). The plasma concentrations of createnine were increased $(p<0.05)$ at D and PE vs. Pre. Urea and AA concentrations were not statistically different (Table 1).

Table 1. Lactate, glucose, creatinine, urea and ascorbic acid (AA) plasmatic concentrations before (Pre), during (D) and post exercise (PE), of junior soccer players (mean \pm DP).

\begin{tabular}{llll}
\hline & Pre & $\mathrm{D}$ & PE \\
\hline $\begin{array}{l}\text { Glucose } \\
\left(\mathrm{mmol} \cdot \mathrm{L}^{-1}\right)\end{array}$ & $5.56 \pm 0.48^{\mathrm{a}}$ & $5.35 \pm 0.44^{\mathrm{a}}$ & $5.08 \pm 0.60^{\mathrm{a}}$ \\
$\begin{array}{l}\text { Lactate } \\
\left(\mathrm{mmol} \cdot \mathrm{L}^{-1}\right)\end{array}$ & $1.79 \pm 0.25^{\mathrm{a}}$ & $8.38 \pm 0.40^{\mathrm{a}, \mathrm{b}}$ & $11.72 \pm 0.31^{\mathrm{a}, \mathrm{b}, \mathrm{c}}$ \\
$\begin{array}{l}\mathrm{Creatinine} \\
\left(\mathrm{mg} \cdot \mathrm{dl}^{-1}\right)\end{array}$ & $1.13 \pm 0.11^{\mathrm{a}}$ & $1.38 \pm 0.10^{\mathrm{a} . \mathrm{b}}$ & $1.48 \pm 0.19^{\mathrm{a}}$ \\
$\begin{array}{l}\mathrm{Urea} \\
\left(\mathrm{mg} \cdot \mathrm{dl}^{-1}\right)\end{array}$ & $37.17 \pm 4.49^{\mathrm{a}}$ & $33.12 \pm 2.29^{\mathrm{a}}$ & $32.21 \pm 4.25^{\mathrm{a}}$ \\
$\begin{array}{l}\text { Ascorbic acid } \\
\left(\mu \mathrm{mol} \cdot \mathrm{L}^{-1}\right)\end{array}$ & $83.40 \pm 4.76^{\mathrm{a}}$ & $86.34 \pm 3.72^{\mathrm{a}}$ & $83.18 \pm 5.73^{\mathrm{a}}$ \\
\hline
\end{tabular}

\footnotetext{
${ }^{\mathrm{a}, \mathrm{b}, \mathrm{c}}$ Different letters in the same row indicate significantly different $(p<0.05)$.
}

The Figure 1(a) shows that LOOHs were not statisticcally different among plasma samples. The MDA concentrations, in Figure 1(b), were significantly increased $(p<0.05)$ at $\mathrm{PE}\left(8.35 \pm 0.83 \mathrm{nmol} \cdot \mathrm{L}^{-1}\right)$ vs. Pre and D $\left(6.69 \pm 0.81\right.$ and $7.03 \pm 1.01 \mathrm{nmol} \cdot \mathrm{L}^{-1}$, respectively). Figure 1(c) shows that CK activity was significantly increased $(p<0.05)$ at PE $\left(304.65 \pm 39.13 \mathrm{U} . \mathrm{I} \cdot \mathrm{L}^{-1}\right)$ vs. Pre $\left(272.01 \pm 49.67\right.$ U.I. $\left.\cdot L^{-1}\right)$. TAP values, showed in Figure 1(d), were decreased $(p<0.05)$ at $\mathrm{PE}(559.95 \pm$ $\left.91.38 \mu \mathrm{mol} \cdot \mathrm{L}^{-1}\right)$ vs. Pre $\left(650.37 \pm 66.53 \mu \mathrm{mol} \cdot \mathrm{L}^{-1}\right)$.

\section{Discussion}

Over the last twenty years, scientific interest in soccer has grown considerably. However, literature with elite soccer players, mainly involving analysis of biomarkers of OS, is still insufficient. Research on junior category is even scarce. Studying junior category is determining in the future success of soccer players' career. Soccer investigations face a challenge of developing an optimum exercise protocol. Such a protocol must represent accurately efforts and intensity of a soccer match to enable sound interpretation and extrapolation of results. In this current study some selected biomarkers of OS in junior soccer players were monitored using an exercise protocol that simulates soccer match activities [15]. The results of this study showed that significant changes occurred in biomarkers of OS and muscle damage immediately after the exercise.

The total distance covered during the test was $10.82 \pm$ $1.72 \mathrm{~km}$. This is similar to the calculated distances covered in professional soccer matches, which are approximately 10 - $12 \mathrm{~km}[2,28]$. During the protocol, players performed activities such as sprinting, walking, jogging $\left(55 \% \mathrm{VO}_{2 \max }\right)$ and cruising $\left(95 \% \mathrm{VO}_{2 \max }\right)$ during respectively $2.94 \%, 44.72 \%, 31.19 \%$ and $11.6 \%$ of the time taken in the protocol, which was in accordance with the time-motion analyses of the activities carried on a soccer match $[10,28]$.

The mean HR of athletes in this study, both during the competitive match and the LIST, were similar to those reported in literature $[11,15,29]$. The significant differences $(p<0.05)$ between the match and LIST could indicate that the LIST protocol is not as intense as game play. This is in agreement with the results published recently where the LIST protocol was compared with a single friendly soccer game [11]. When a player was his own control within each group, the practice of LIST or match represented the same physical effort in terms of HR. The significant difference found in mean HR between match and LIST may be related to the different positions of players on the field during the game, although further research is needed to confirm this hypothesis. 


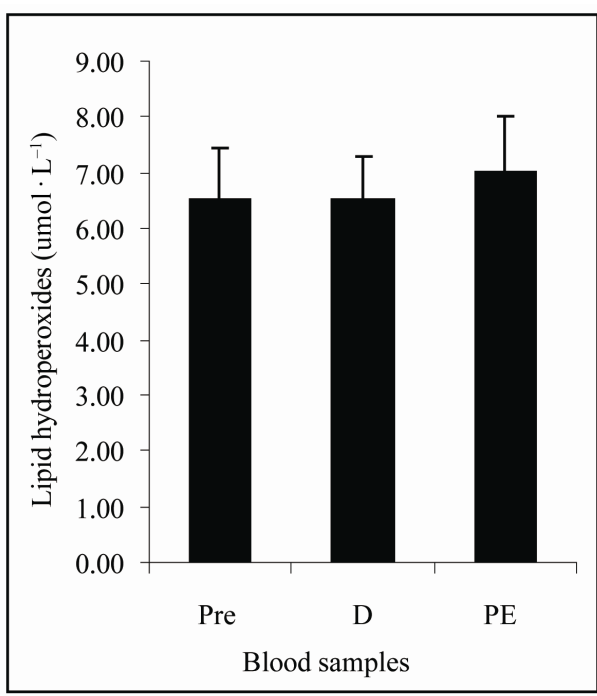

(a)

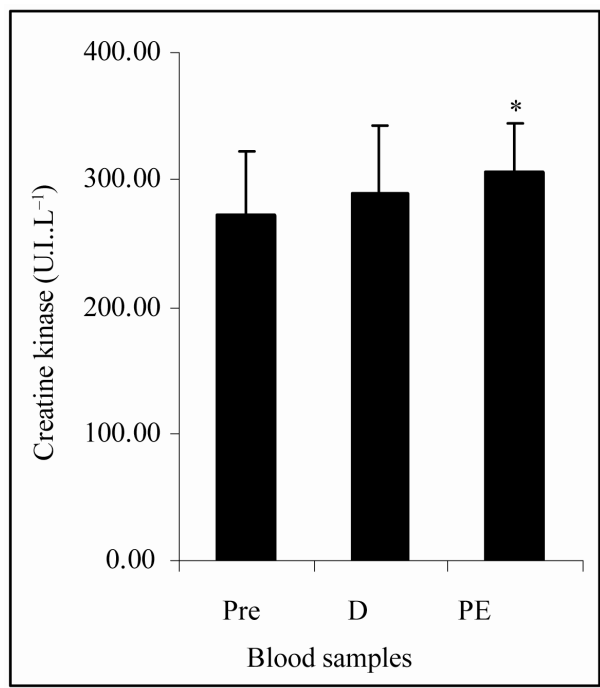

(c)

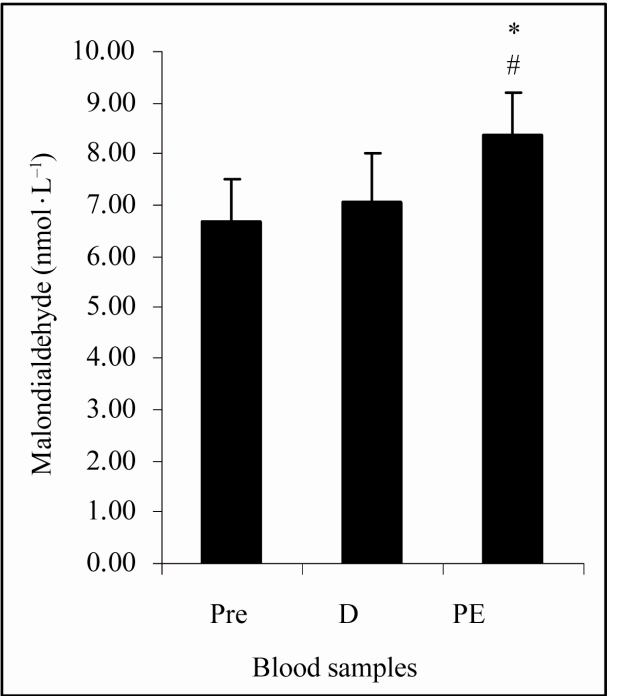

(b)

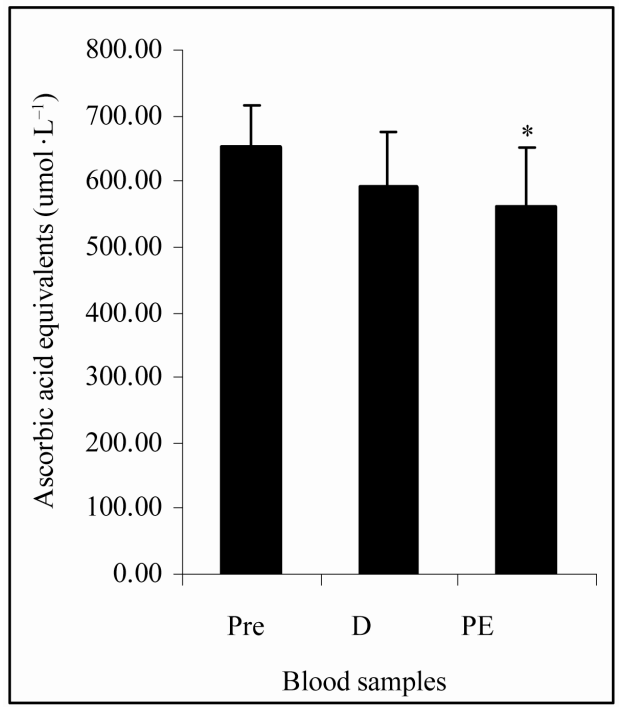

(d)

Figure 1. (a) Plasma lipid hydroperoxides (LOOHs) concentrations; (b) Plasma malondialdehyde (MDA) concentrations; (c) Plasma creatine kinase (CK) activity; (d) Total plasma antioxidant potential (TAP) as ascorbic acid (AA) equivalents concentrations in FRAP analysis; before (Pre), during (D), and post exercise (PE) of junior soccer players (mean \pm SD). "Significant difference $(p<0.05)$ with Pre. "Significant difference $(p<0.05)$ with $\mathrm{D}$.

The intensity of effort was also assessed by lactate levels. The data, in this study, indicate that there was an organic response to exercise due to increased lactate at $\mathrm{D}$ and PE vs. Pre $(p<0.05)$ (Table 1), which was in agreement with other researches $[15,29]$. Intense exercises can increase the formation of FR and when this increase promotes negative effects in organism, the OS state can be installed. Lipid peroxidation is the most described consequence of the OS [30] and leads to the formation of a wide array of oxidation products such as $\mathrm{LOOHs}$ and MDA [7]. The lipids peroxidation induces damage of cellular membranes which can cause the release of tissue intracellular substances into the blood. One of such compounds is CK, which is a marker of muscle cellular damage and OS $[7,8]$. Normally the antioxidant defense system can avoid the installation of the OS by the action of many antioxidant substances, which can be measured as TAP and/or by the analysis of a specific antioxidant, such as AA [8].

The plasma concentrations of LOOHs, MDA, CK, TAP and AA at D in the present study were similar to Pre levels (Figures 1(a)-(d) and Table 1). However, significant dif- 
ferences in $\mathrm{CK}, \mathrm{MDA}$ and TAP at PE suggest alterations in those biomarkers, in the early stage of post exercise period, by particular physical activity that occur during the LIST.

Zoppi et al. [30] demonstrated that OS, muscle damage markers and the antioxidant defense system of soccer players can be significantly altered after a competitive season. Ascensão et al. [10], evaluating changes in plasma biomarkers of OS after a single soccer match, demonstrated that plasma concentrations of MDA and CK were increased 30 minutes after the end of game and remained elevated for 72 hours. Later, those results were reinforced in the study of Magalhães et al. [11], who compared the same biochemical parameters after one friendly game and the LIST. The present study approached the analysis of OS parameters during and immediately after exercise, to detect the initiation of blood metabolites alterations. Future intervention studies should indicate if the administration of antioxidant at this early stage of biochemical changes would promote adequate recovery of athletes. Some authors may consider that the LIST protocol does not represent the same effort as a match. Magalhães et al. [11], for example, demonstrated that no significant differences in CK values were found between one single friendly game and the LIST, but, the MDA plasmatic concentrations had greater increase after the game than the LIST. The authors suggested that the results from the LIST might be underestimated; however, once it is not possible to well control game variables [15] more replicates are required for such affirmation including investigation of soccer players also under competitive games.

Regarding TAP the literature is quite controversial [10, 31]. When evaluated alone, this parameter might not be satisfactorily consistent to estimate the impact of physical activity. Nonetheless, some conclusions may be made when considered along with other biochemical parameters, such as MDA, LOOHs and CK. Here, the concomitant decrease in TAP values and the increase in MDA and CK right after the LIST may indicate alterations in the body antioxidant defense system. However, some other parameters of oxidative damage, such as antioxidant enzymes activity (not analyzed), should furnish more support to confirm these data.

It is reasonably accepted that the constant risk of OS may place junior soccer players in the frontier between health and disease, beyond the intense routine of training and confronting during a competitive season. It is not clear in the literature the influence of changes in those OS markers analyzed in this study over athletic performance. Also, it is not well known if it would have different profile under supplementation with antioxidant substances normally used to attenuate some of the blood parameters indicative of OS.

\section{Conclusions}

This work demonstrated that the LIST protocol induced significant changes in some selected biomarkers of oxidative stress in the early stage of recovery of professional junior soccer players. Immediately after the exercise there was a significant decrease in total plasma antioxidant potential while malondialdehyde and creatine kinase had increased. Data suggest that nutritional intervention with antioxidant substances during or post exercise may be considered for players' effective recovery before subsequent sport events. However, further investigations are needed to elucidate if metabolic parameters monitored, in the current study, would be altered by dietetic antioxidant substances administration. Data provided by this study are unique and important for professional soccer players because of their intense daily routines of training and competing and thus their constant exposure risks of injuries and other consequences of free radicals generation.

\section{Ackowledgements}

This work was supported by Fundação de Amparo à Pesquisa do Estado do Rio de Janeiro (FAPERJ) and Conselho Nacional de Desenvolvimento Científico e Tecnológico (CNPQ).

We thank the soccer players involved in the study for their committed participation and the technical assistance of Jamilce Araújo, Bruno Costa, Antonio Garcia, Flávio Vignoli, Alex Rittes and Guilherme Amaral from the football club. We are grateful to Felipe Detommaso for performing the blood collection and to the students and professionals who assisted in the research, Natasha Kelber, Andrea Ferreira, Homero Júnior and Ana Cristina Barreto.

\section{REFERENCES}

[1] J. Hoff and J. Helgerud, "Endurance and Strength Training for Soccer Players-Physiological Considerations," Sports Medicine, Vol. 34, No. 3, 2004, pp. 165-180. doi:10.2165/00007256-200434030-00003

[2] T. Stølen, K. Chamari, C. Castagna and U. Wisløff, "Physiology of Soccer: An Update," Sports Medicine, Vol. 35, No. 6, 2005, pp. 501-536.

[3] J. Strøyer, L. Hansen and K. Klausen, "Physiological Profile and Activity Pattern of Young Soccer Players during Match Play," Medicine and Science in Sports and Exercise, Vol. 36, No. 1, 2004, pp. 168-174. doi:10.1249/01.MSS.0000106187.05259.96

[4] J. Helgerud, L. C. Engen, U. Wisløff and J. Hoff, "Aerobic Endurance Training Improves Soccer Performance," Medicine and Science in Sports and Exercise, Vol. 33, No. 11, 2001, pp. 1925-1931. doi:10.1097/00005768-200111000-00019

[5] C. B. Wragg, N. S. Maxwell and J. H. Doust, "Evaluation 
of the Reliability and Validity of a Soccer-Specific Field Test of Repeated Sprint Ability," European Journal of Applied Physiology, Vol. 83, No. 1, 2000, pp. 77-83. doi:10.1007/s004210000246

[6] N. B. Vollaard, J. P. Shearman and C. E. Cooper, "Exercise-Induced Oxidative Stress: Myths, Realities and Physiological Relevance," Sports Medicine, Vol. 35, No. 12, 2005, pp. 1045-1062. doi:10.2165/00007256-200535120-00004

[7] M. L. Urso and P. M. Clarkson, "Oxidative Stress, Exercise, and Antioxidant Supplementation," Toxicology, Vol. 189, No. 1-2, 2003, pp. 41-54. doi:10.1016/S0300-483X(03)00151-3

[8] J. Finaud, G. Lac and E. Filaire, "Oxidative Stress: Relationship with Exercise and Training," Sports Medicine, Vol. 36, No. 4, 2006, pp. 327-358. doi:10.2165/00007256-200636040-00004

[9] C. K. Sen, "Antioxidant and Redox Regulation of Cellular Signaling: Introduction," Medicine and Science in Sports and Exercise, Vol. 33, No. 3, 2001, pp. 368-370. doi:10.1097/00005768-200103000-00005

[10] A. Ascensão, A. Rebelo, E. Oliveira, F. Marques, L. Pereira and J. Magalhães, "Biochemical Impact of a Soccer Match-Analysis of Oxidative Stress and Muscle Damage Markers throughout Recovery," Clinical Biochemistry, Vol. 41, No. 10-11, 2008, pp. 841-851. doi:10.1016/j.clinbiochem.2008.04.008

[11] J. Magalhães, A. Rebelo, E. Oliveira, J. R. Silva, F. Marques and A. Ascensão, "Impact of Loughborough Intermittent Shuttle Test Versus Soccer Match on Physiological, Biochemical and Neuromuscular Parameters," European Journal of Applied Physiology, Vol. 108, No. 1, 2010, pp. 39-48. doi:10.1007/s00421-009-1161-Z

[12] J. Cholewa, S. Poprzecki, A. Zajac, and Z. Waskiewicz, "The Influence of Vitamin $\mathrm{C}$ on Blood Oxidative Stress Parameters in Basketball Players in Response to Maximal Exercise," Science \& Sports, Vol. 23, No. 3-4, 2008, pp. 176-182. doi:10.1016/i.scispo.2008.01.004

[13] A. Mastaloudis, S. W. Leonard and M. G. Traber, "Oxidative Stress in Athletes during Extreme Endurance Exercise," Free Radical Biology and Medicine, Vol. 37, No. 7, 2001, pp. 911-922. doi:10.1016/S0891-5849(01)00667-0

[14] A. Mastaloudis, J. D. Morrow, D. W. Hopkins, S. Devaraj and M. G. Traber, "Antioxidant Supplementation Prevents Exercise-Induced Lipid Peroxidation, But Not Inflammation, in Ultramarathon Runners," Free Radical Biology and Medicine, Vol. 36, No. 10, 2004, pp. 13291341. doi:10.1016/j.freeradbiomed.2004.02.069

[15] C. W. Nicholas, F. E. Nuttall and C. Williams, "The Loughborough Intermittent Shuttle Test: A Field Test That Simulates the Activity Pattern of Soccer," Journal of Sports Sciences, Vol. 18, No. 2, 2000, pp. 97-104. doi:10.1080/026404100365162

[16] C. W. Nicholas, K. Tsintzas, L. Boobis and C. Williams, "Carbohydrate-Electrolyte Ingestion during Intermittent High-Intensity Running," Medicine and Science in Sports and Exercise, Vol. 31, No. 9, 1999, pp. 1280-1286. doi:10.1097/00005768-199909000-00008

[17] S. D. Patterson and S. C. Gray, "Carbohydrate-Gel Supplementation and Endurance Performance during Intermittent High-Intensity Shuttle Running," International Journal of Sport Nutrition and Exercise Metabolism, Vol. 17, No. 5, 2007, pp. 445-455.

[18] D. Thompson, C. Williams, M. Kingsley, C. W. Nicholas, H. K. Lakomy, F. McArdle and M. J. Jackson, "Muscle Soreness and Damage Parameters after Prolonged Intermittent Shuttle-Running Following Acute Vitamin C Supplementation," International Journal of Sports Medicine, Vol. 22, No. 1, 2001, pp. 68-75. doi:10.1055/s-2001-11358

[19] D. Thompson, E. D. Bailey, E. J. Hill, E. T. Hurst, J. R. Powell and E. C. Williams, "Prolonged Vitamin C Supplementation and Recovery from Eccentric Exercise," European Journal of Applied Physiology, Vol. 92, No 1-2, 2004, pp. 133-138. doi:10.1007/s00421-004-1064-y

[20] A. S. Jackson and M. L. Pollock, "Generalized Equations for Predicting Body Density of Men,” The British Journal of Nutrition, Vol. 40, No. 3, November 1978, pp. 497-504. doi:10.1079/BJN19780152

[21] L. A. Léger and J. Lambert, "A Maximal Multistage 20-m Shuttle Run Test to Predict $\mathrm{VO}_{2}$ Max," European Journal of Applied Physiology and Occupational Physiology, Vol. 49, No. 1, 1982, pp. 1-12. doi:10.1007/BF00428958

[22] N. R. Rodriguez, N. M. DiMarco, S. Langley, American Dietetic Association, Dietetians of Canada and American College of Sports Medicine, "Position of the American Dietetic Association, Dietitians of Canada, and the American College of Sports Medicine: Nutrition and Athletic Performance," Journal of the American Dietetic Association, Vol. 109, No. 3, 2009, pp. 509-527. doi:10.1016/j.jada.2009.01.005

[23] E. Bobrowicz, J. W. Naskalski and A. Siedlecki, "Preanalytical Factors in Human Plasma Ascorbate Assay," Clinical Chimica Acta, Vol. 314, No. 1-2, 2001, pp. 237 239. doi:10.1016/S0009-8981(01)00577-0

[24] E. Södergren, J. Nourooz-Zadeh, L. Berglund and B. Vessby, "Re-Evaluation of the Ferrous Oxidation in Xylenol Orange Assay for the Measurement of Plasma Lipid Hydroperoxides," Journal of Biochemical and Biophysical Methods, Vol. 37, No. 3, 1998, pp. 137-146. doi:10.1016/S0165-022X(98)00025-6

[25] J. Nourooz-Zadeh, J. Tajaddini-Sarmadi and S. P. Wolff, "Measurement of Plasma Hydroperoxide Concentrations by the Ferrous Oxidation-Xylenol Orange Assay in Conjuncttion with Triphenylphosphine," Analytical Bio-Chemistry, Vol. 220, No. 2, 1994, pp. 403-409. doi:10.1006/abio.1994.1357

[26] F. Karatas, M. Karatepe and A. Baysar, "Determination of Free Malondialdehyde in Human Serum by High-Performance Liquid Chromatography," Analytical Biochemistry, Vol. 311, No. 1, 2002, pp. 76-79. doi:10.1016/S0003-2697(02)00387-1 
[27] I. F. Benzie and J. J. Strain, "The Ferric Ability of Plasma (FRAP) as a Measure of 'Antioxidant Power': The FRAP Assay," Analytical Biochemistry, Vol. 239, No. 1, 1996, pp. 70-76. doi:10.1006/abio.1996.0292

[28] M. Mohr, P. Krustrup and J. Bangsbo, "Match Performance of High-Standard Soccer Players with Special Reference to Development of Fatigue," Journal of Sports Sciences, Vol. 21, No. 7, 2003, pp. 519-528. doi:10.1080/0264041031000071182

[29] P. Krustrup, M. Mohr, A. Steensberg, J. Bencke, M. Kjaer and J. Bangsbo, "Muscle and Blood Metabolites during a Soccer Game: Implications for Sprint Performance," Medicine and Science in Sports and Exercise, Vol. 38, No. 6, 2006, pp. 1165-1174. doi:10.1249/01.mss.0000222845.89262.cd

[30] C. C. Zoppi, R. Hohl, F. C. Silva, F. L. Lazarim, J. M. Neto, M. Stancanneli and D. V. Macedo, "Vitamin C and E Supplementation Effects in Professional Soccer Players under Regular Training," Journal of the International Society of Sports Nutrition, Vol. 3, 2006, pp. 37-44. doi:10.1186/1550-2783-3-2-37

[31] S. R. McAnulty, L. S. McAnulty, D. C. Nieman, J. D. Morrow, L. A. Shooter, S. Holmes, C. Heward and D. A. Henson, "Effect of Alpha-Tocopherol Supplementation on Plasma Homocysteine and Oxidative Stress in Highly Trained Athletes before and after Exhaustive Exercise," The Journal of Nutritional Biochemistry, Vol. 16, No. 9, 2005, pp. 530-537. doi:10.1016/j.jnutbio.2005.02.001 